\title{
Seeking the Optimal Time for Integrated Curriculum in Jinan University School of Medicine
}

\author{
Sanqiang Pan ${ }^{1}$, Xin Cheng ${ }^{1,2}$, Yanghai Zhou ${ }^{3}, \mathrm{Ke} \mathrm{Li}^{1} \&$ Xuesong Yang ${ }^{1,2}$ \\ ${ }^{1}$ Department of Clinical Medicine, Medical College, Jinan University, Guangzhou, China \\ ${ }^{2}$ Key Laboratory for Regenerative Medicine of the Ministry of Education, Jinan University, Guangzhou, China \\ ${ }^{3}$ The Teaching \& Learning Office, the First Affiliated Hospital, Jinan University, Guangzhou, China \\ Correspondence: Xuesong Yang, Department of Clinical Medicine, Medical College, Jinan University, Guangzhou, \\ 510632, China. Tel: 86-20-8522-8316. E-mail: yang_xuesong@126.com
}

Received: October 13, 2016

Accepted: November 1, 2016

Online Published: November 3, 2016

doi:10.5430/ijhe.v6n1p25

URL: http://dx.doi.org/10.5430/ijhe.v6n1p25

\begin{abstract}
The curricular integration of the basic sciences and clinical medicine has been conducted for over 40 years and proved to increase medical students' study interests and clinical reasoning. However, there is still no solid data suggesting what time, freshmen or year 3 , is optimal to begin with the integrated curriculum. In this study, the integrated courses on cardiovascular and respiratory systems were performed to part of year 1 and year 3 medical students while non-participant students acted as control. We tried to explore the optimal time through comparison of the exam results and questionnaire of participated students. It was demonstrated that year 3 participant students got better exam score than year 1 students did, and the questionnaire showed that it might be due to the year 1 participants difficultly caught up with the contents of integrated courses without appropriate background knowledge. Three years later, the participant students got higher ability to analytical thinking of clinical diseases in comparison to non-participant students, while it did not improve the acquirement of their clinical practical skills. Taken together, our study in Jinan University School of Medicine indicated that the integrated courses would be approximately effective if combined to conventional medical teaching at year 3 after the students obtain relevant basic sciences knowledge.
\end{abstract}

Keywords: Medical student, Integrated course, Teaching, PBL, OSCE

\section{Introduction}

The conventional curricula of medical education consist of two and half years of basic sciences and two and half years of clinical sciences followed. A medical integrated curriculum refers to an interdisciplinary course that brings together medical basic, and/or clinical sciences into an organized unit based on body organs or organ systems (Muller, Jain, Loeser, \& Irby, 2008). McGill University was the first university to implement integrated basic sciences and clinical knowledge for medical students in the 1970s (Patel, \& Dauphinee, 1984). More than dozens of medical schools offered the integrated courses in U.S. and Canada in the 1980s (Spencer, Brosenitsch, Levine, \& Kanter, 2008). A few Chinese and Japanese medical schools have begun the integrated curricula in recent years (see e.g., Huang et al., 2014; Rao, \& Rao, 2007). Generally, integrated curricula have been widely adopted all over the world at moment since the curricular integration was designed to enhance medical students' learning efficiency and understand clinical medicine well.

The curricular integration includes horizontal integration and vertical integration. The horizontal integration means the curricular integration among basic sciences or among clinical sciences, while the curricular integration of basic sciences and clinical medicines is called as vertical integration (see e.g., Dahle et al., 2002; Lie, 1995; Rajan, Jacob, \& Sathyendra, 2016). Compared to the horizontal integration generally implemented in the beginning of medical study, the vertical integration was more popularly carried out, because the integration of basic and clinical sciences increases students' study interest, promotes the transfer of basic science knowledge to the clinical questions, and meets the needs of training current physicians (see e.g., Bandiera, Boucher, Neville, Kuper, \& Hodges, 2013; Brynhildsen et al., 2002; Davis, \& Harden, 2003; Muller, 1984). However, the time arrangement for vertical integrated curriculum varies with different medical schools. Concerning about the timing for the integrated curriculum, it was arranged at the students of grade 1 or 2 to after students studied human anatomy in University of Wisconsin, University of Pittsburgh and Dartmouth Medical School (see e.g., Pipas et al., 2004). Nevertheless, some American and Canadian universities integrate some aspects of basic sciences into clinical medicines at year 3 or 4 
medical students (Spencer, Brosenitsch, Levine, \& Kanter, 2008; Croen, Lief, \& Frishman, 1986). It is noteworthy that little attention has been paid to the optimal time for the integrated curriculum in different medical schools, in other word, what time is the best for kicking off the integrated curriculum, so that students learn medical knowledge more efficiently.

Jinan University School of Medicine implemented the vertical integrated curriculum using the PBL (problem-based learning) approach as elective courses approach from 2012. We attempted the integrated curriculum on cardiovascular and respiratory systems for year 1 and year 3 medical students respectively. In this study, we compared the effects of integrated curriculum between the year 1 and year 3 medical students. The aim of this study is to explore the optimal time for the medical students in Jinan University School of Medicine to access integrated curriculum teaching.

\section{Methods}

\subsection{Design and Participants}

Because there is a close relationship between chronic pulmonary diseases and cardiovascular diseases, we selected the vertical integrated courses of the respiratory (Table 1) and cardiovascular systems (Table 2) to part of year 1 or year 3 medical undergraduates during summer vacation in 2012. The vertical integrated courses, as elective courses, were arranged according to the mature cases reported in other medical schools (1) the MBChB Programme of Medicine, The Chinese University of Hong Kong. The descriptions about the curriculum design could be obtained through visiting the website for more information http://www.med.cuhk.edu.hk/mcu/; (2) Integrated Curriculum, medical school of Shantou University (http://www.med.stu.edu.cn/list-18.html). Each curriculum integrated some aspects of basic science into clinical medicine was implemented for 45 hours. The teaching approaches consisted of intern, lectures, demonstration and PBL. The lecturers come from basic sciences and clinical sciences at Jinan University School of Medicine, and all of them are either associate professors or professors. In addition, all of the lecturers from different disciplines were previously trained by the PBL-experienced teachers from University of Hong Kong in the PBL workshop. The detailed contents, format and timing of the integrated courses were described in Table 1 and 2. Here, the first-year students just studied the human anatomy while the third-year students nearly finished all of basic medical sciences including physiology, biochemistry, pharmacology, microbiology, immunology and pathology/pathphysiology. The students were not allowed to attend the integrated curriculum unless their average scores were at or above 82 (Grade B). The student numbers of participants in year 1 and year 3 are 43 and 25 respectively in 2012.

In order to evaluate the effect of the integrated courses between the first-year and third-year students, the final exam was carried out after each integrated course finished. The final exam was to analyze a clinical case that included six questions from basic science and clinical medicine. Meanwhile, the questionnaires for the integrated courses would be usually performed among the participants.

Furthermore, in order to further investigate the effect of the integrated courses on the study of those third-year students' long-term clinical sciences, we carefully analyzed their clinical exam scores when the first student body entered clinical science study 2 year later. 26 other non-participant third-year medical students were chosen as control groups. The control students are selected randomly. We compared the scores of objective structured clinical examinations (OSCE) between participants and non-participants. OSCE include: 1) thoracentesis, lumbar puncture, bone marrow puncture, abdominocentesis, 2) physical examination, 3) analysis of electrocardiogram (ECG), 4) cardiopulmonary resuscitation, 5) gynecologic examination, 6) surgical stitches and dressing, 7) surgical discussion and suture. 8) pediatric history taking, 9) clinical case analysis (Figure 3).

\subsection{Data Analysis}

The data produced were presented as mean \pm standard deviation (SD). ANOVA tests were performed using a Graphpad Prism 5 software package (Graphpad Software, CA, USA). Samples were considered to be significantly different from control when $p<0.05$, and extremely significantly different when $p<0.01$.

\section{Results}

\subsection{The Examination Results from Year 3 Students are Better than the one from Year 1 Students}

The integrated courses of cardiovascular and respiratory systems were offered to some year 1 and year 3 medical students in Jinan University School of Medicine during summer vacation from 2012. The integrated courses were designed according to the integrative requirements in the two systems, and the arrangement of contents and lecture/practice in the both integrated courses were listed in detail in Table 1 and Table 2. The participants from year 1 and year 3 students were chosen on a voluntary basis. The exams would be carried out among the participants from both of year 1 and year 3 students following the completion of the integrated courses. From the examination results, 
we can see that the exam scores from year 3 students are significantly better than the ones from year 1 students in both subjects of cardiovascular (year $3=78.59 \pm 0.34, \mathrm{n}=25$; year $1=74.15 \pm 9.71, \mathrm{n}=17$; $p<0.05$ ) and respiratory systems (year $3=77.43 \pm 6.89, \mathrm{n}=25$; year $1=65.87 \pm 14.52, \mathrm{n}=26 ; p<0.01$ ) (Figure 1 ).

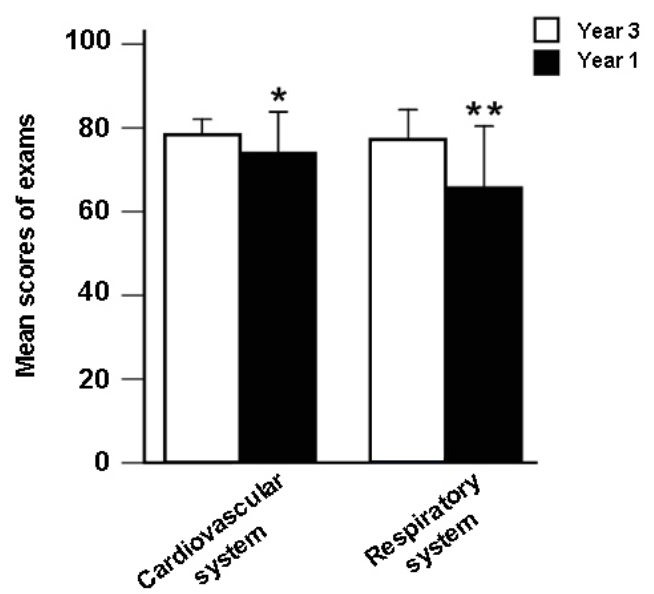

Figure 1. The mean scores of the exams at the end of integrated courses

The exams were carried out in the year 1 and year 3 medical students when the integrated courses about cardiovascular and respiratory system ended. The hundred percent point systems are employed in the exams. The bar chart shows the comparisons of exams about cardiovascular and respiratory system between year 1 and year 3 medical students. * $p<0.05$ compared to year $1, * * p<0.01$ compared to year 1 .

Table 1 . The integrated course of cardiovascular system

\begin{tabular}{lll}
\hline Contents & Format & Hours \\
\hline Coronary heart diseases, hypertension and heart failure & Intern (or clinical rotation) & 3 \\
Anatomy of cardiovascular system & Practice & 2 \\
Histology and development of cardiovascular system & Lecture & 2 \\
Pumping action of the heart, transmembrane potential & Lecture & 2 \\
and electrical activity of cardiac muscle & & \\
Arterial blood pressure & Lecture & 2 \\
Regulation of cardiovascular function and blood volume & Lecture & 2 \\
Analysis of electrocardiogram & Demonstration & 2 \\
Cardiac insufficiency & Lecture & 4 \\
Pathology of atherosclerosis, aneurysm and hypertension & Lecture & 2 \\
Pathology of atherosclerosis, aneurysm and hypertension & Lab & 2 \\
Coronary atherosclerosis (PBL 1) & PBL & 2 \\
Radiology and imaging of cardiovascular system (X-ray) & Demonstration \\
Radiology and imaging of cardiovascular system (Ultrasonic & Demonstration \\
and interventional imaging) & & 2 \\
Atherosclerosis and hypertension & Lecture & 2 \\
Heart failure & Lecture & \\
Drugs for heart failure & Lecture & 2 \\
Anti-angina drugs & Lecture & 2 \\
Anti-atherosclerotic drugs & Lecture & 2 \\
Antihypertensive drugs & Lecture & 2 \\
Coronary atherosclerosis (PBL 2) & PBL & 2 \\
Review & Q \& A & 2 \\
\hline & & 2 \\
& & 2 \\
\hline
\end{tabular}


Table 2. The integrated course of respiratory system

\begin{tabular}{llc}
\hline Contents & Format & Hours \\
\hline Bronchiogenic carcinoma, pneumonia and pleural effusion & Intern (or clinical rotation) & 4 \\
Anatomy of respiratory system & Lecture & 2 \\
Histology and development of respiratory system & Lecture & 2 \\
Gas exchange, gas transport in the blood, regulation & Lecture & 2 \\
of respiratory movement & & \\
Pathology in respiratory diseases (pulmonary infection, & Lecture & 4 \\
carcinoma of the respiratory system, cytological examination ) & & \\
& Lab & \\
Insufficiency of respiration & Lecture & 4 \\
Radiology and imaging of respiratory system & Lecture & 4 \\
& Demonstration & \\
Blood gas analysis & Lecture & 2 \\
Bronchiogenic carcinoma (PBL 1) & PBL & 2 \\
Anti-inflammatory, anti-tuberculosis and antineoplastic drugs & Lecture & 4 \\
Pneumonia & Lecture & 2 \\
Pleural effusion and pulmonary tuberculosis & Lecture & 2 \\
Chronic obstructive pulmonary disease and respiratory failure & Lecture & 3 \\
Search references in bronchiogenic carcinoma and & Practice & 2 \\
pleural effusion & & 2 \\
Bronchiogenic carcinoma & Lecture & 2 \\
Bronchiogenic carcinoma (PBL 2) & PBL & 2 \\
Review & Q \& A & 2 \\
\hline year 3 & & 2 \\
\hline
\end{tabular}

3.2 The year 3 students had more positive attitude toward the integrated courses than year 1 students

After the completion of the integrated courses, we usually inquired the participations' opinion for the establishment of integrated courses. From the feedback questionnaire from the participants of year 1 and year 3 students, one trend is more and more obvious, which is that year 3 participants are more interested in taking part in the integrated course in comparison to year 1 students since they simply more benefited from the study of integrated course. In this point, there is no difference between cardiovascular and respiratory systems. We could see that $97 \%$ year 3 participants had positive attitude and only 3\% participants had neutral attitude toward the integrated courses (Figure 2). Meanwhile, the positive attitude toward to the integrated courses in year 1 participants was $74 \%$, but $19 \%$ participants from year 1 felt negative attitude toward the integrated courses, and 7\% participants were neutral (Figure 2).

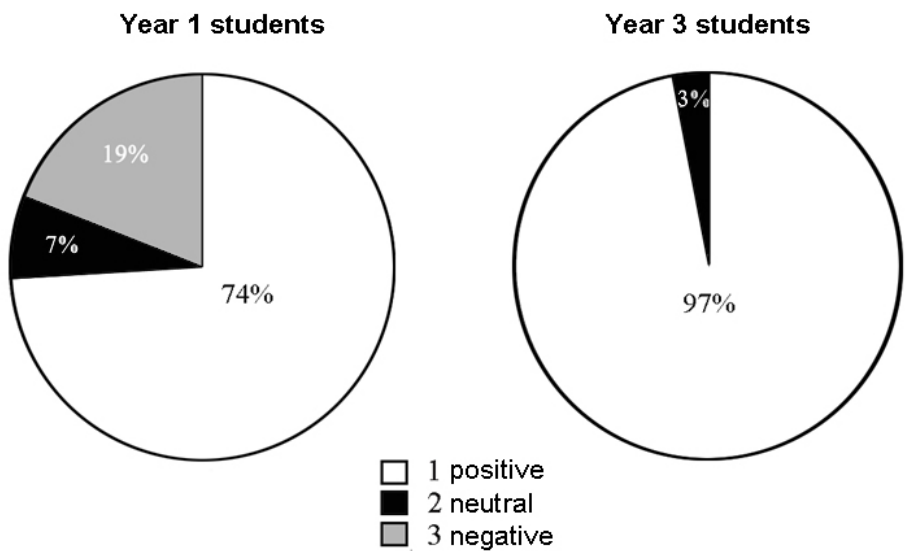

Figure 2. The questionnaire survey at the end of integrated courses 
The questionnaire survey about the attitude toward the integrated course was carried out in the year 1 and year 3 medical students when the integrated courses about cardiovascular and respiratory system ended. The hundred percent point systems are employed in the questionnaire survey. The left-side circular scale chart shows the attitude toward the integrated course as percentage in year 1 medical students. The right-side circular scale chart shows the attitude toward the integrated course as percentage in year 3 medical students.

To investigate what caused the different attitudes toward the integrated courses, we further asked the year $1(n=43)$ and year $3(\mathrm{n}=25)$ participant students to answer the questionnaire, in which improve clinical diagnosis, analysis problem, improve clinical reasoning, communication skill, system integrity, increase interest in course, self study, PBL and course difficulty are included (Table 3). In the subjects of questionnaire, the most difference between year 1 and year 3 students' replies is in the course difficulty. 33\% year 1 participant claimed that the integrated courses were difficulty, and the number is much higher than the $10 \%$ from year 3 participants. In another word, most of year 3 students $(87 \%)$ in the course feel easy for attending the courses, but only about half of year 1 students (58\%) didn't feel difficulty to listen to the integrated courses (Table 3).

Table 3. The questionnaires of integrated courses from year 1 and year 3 students

Questionnaire of the integrative courses from year 1 students ( $n=43$ )

\begin{tabular}{llll}
\hline Item & Positive & Neutral & Negative \\
\cline { 2 - 4 } Improve clinical diagnosis & $86 \%$ & $12 \%$ & $2 \%$ \\
Analysis problem & $89 \%$ & $9 \%$ & $2 \%$ \\
Improve clinical reasoning & $79 \%$ & $19 \%$ & $2 \%$ \\
Communication skill & $63 \%$ & $23 \%$ & $14 \%$ \\
System integrity & $94 \%$ & $2 \%$ & $4 \%$ \\
Increase interest in course & $96 \%$ & $2 \%$ & $2 \%$ \\
Self study & $86 \%$ & $7 \%$ & $7 \%$ \\
PBL & $84 \%$ & $12 \%$ & $4 \%$ \\
Course difficulty & $33 \%$ & $9 \%$ & $58 \%$ \\
\hline Prative courses from year 3 students (n=29) & \\
\hline Item & Positive & Neutral & Negative \\
\hline Improve clinical diagnosis & $93 \%$ & $7 \%$ & $0 \%$ \\
Analysis problem & $100 \%$ & $0 \%$ & $0 \%$ \\
Improve clinical reasoning & $72 \%$ & $24 \%$ & $4 \%$ \\
Communication skill & $59 \%$ & $31 \%$ & $10 \%$ \\
System integrity & $100 \%$ & $0 \%$ & $0 \%$ \\
Increase interest in course & $97 \%$ & $3 \%$ & $0 \%$ \\
Self study & $100 \%$ & $0 \%$ & $0 \%$ \\
PBL & $87 \%$ & $10 \%$ & $3 \%$ \\
Course difficulty & $10 \%$ & $3 \%$ & $87 \%$
\end{tabular}

In order to further assess whether the vertical integrated curriculum is really difficult for first-year students, we collected the means scores of the medical students enrolled in 2014 on their conventional medical courses, including anatomy, histology and embryology, physiology, cell biology, medical physics, biochemistry, human health and disease. And we compared the means scores of medical students, which come respectively from their integrated and conventional medical courses. The result showed that there was significant difference between the exam results of integrated and conventional medical courses (integrated $=72.84 \pm 9.85$, conventional $=78.84 \pm 5.77, p<0.05$ ) (Figure 3). The results showed that the first-year students obtained higher exam scores in conventional courses than in integrated courses, indicating that the integrated curricula are more difficult to study for the first-year medical students. 


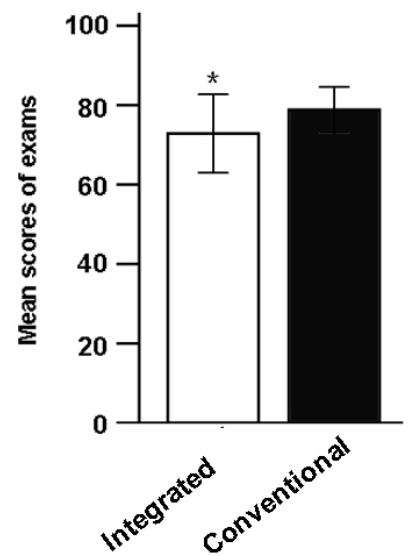

Figure 3. The mean scores of first-year students' exams from traditional medical sciences and vertical integrated courses. The means mean scores of first-year medical students $(n=43)$ from two integrated and eight conventional medical courses were compared. The bar chart shows the mean scores. ${ }^{*} p<0.05$ compared to conventional medical

courses.

\subsection{The integrated courses impact on the participated students' clinical science studies}

To investigate whether or not the integrated course study impact on the studies of those students after they entered the stage of clinical science study, we employed OSCE to assess the mastering ability of fundamental clinical skill training among those medical students after training with the variety of simulations, showing the subjects of OSCE exams are all relevant to integrated analysis ability (Figure 4). This might indicate that the training of integrated course in early stage of their study indeed promote their ability for clinical study and practice later on.

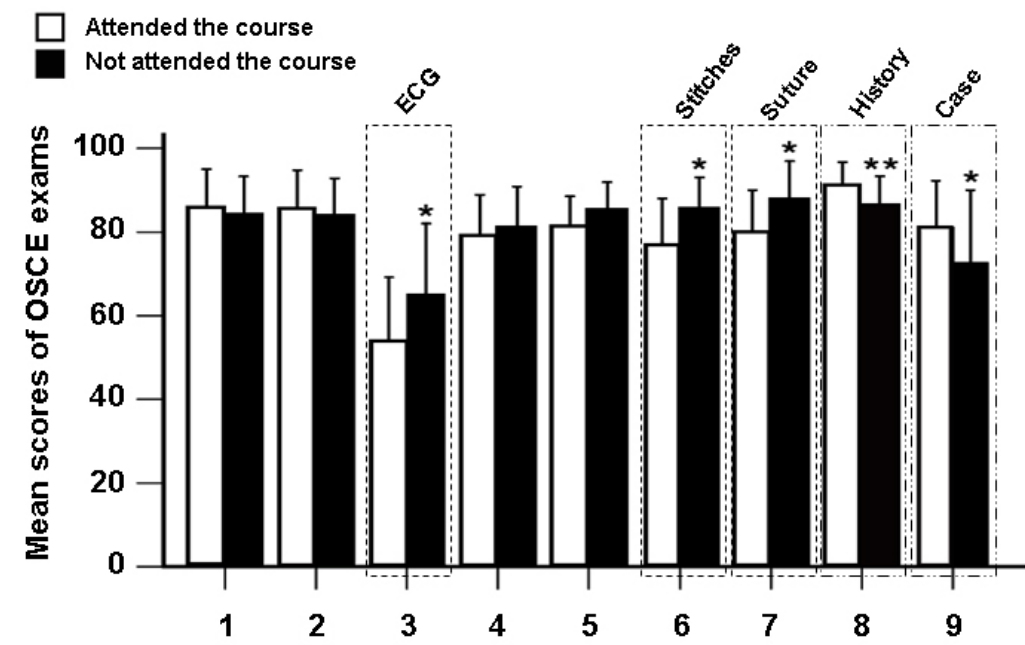

Figure 4. The mean scores of students' exams from the OSCE following the clinical skill training with simulations. OSCE was carried out among the medical students who attended the integrated courses and who did not attend the courses when the year 3 participant students entered into the study of clinical sciences several years later.

The bar chart shows the comparison of mean scores of the students on OSCE exams, in which the exam subjects were marked. $* p<0.05$ compared to non-participants, $* * p<0.01$ compared to non-participants.

\section{Discussion}

It has been well known that integrated course teaching with PBL model had deeply shocked on our conventional medical education, the teaching in classroom respectively by the staff from different basic and clinical discipline, worldwide in the past several decades (i.e., Abraham, Vinod, Kamath, Asha, \& Ramnarayan, 2008; Chen, Lai, Lu, Tsai, Chiang, Huang, \& Yu, 2008; Fincham, \& Shuler, 2001; Jones, McArdle, \& O'Neill, 2002; Oda, Koizumi, 2008). 
The impact of medical education reform has unlimitedly touched the campus of Jinan University School of Medicine, in which the medical students have constantly been taught and trained as conventional teaching approach until several years ago. Therefore, the integrated courses were performed at Jinan University School of Medicine three years ago. Since it is the initial experimental stage in our campus, the integrated curricula were only opened to medical students during the summer vacation, so that the normal schedule of ordinary teaching was not disturbed. The participants were mainly chosen in accordance with the principle of voluntary. However, one question we have to face is to hunt for the optimal point-in-time for the integrated course. Some schools implement the integrated curriculum at the first-year students (Pipas, Peltier, Fall, Olson, Mahoney, Skochelak, \& Gjerde, 2004), while some at the third-year or fourth-year students (Spencer, Brosenitsch, Levine, \& Kanter, 2008). So far, there has not been evidence showing what time is the best to begin the integrated curriculum for medical students. Here, we meaningfully chose two populations of students who are from year 1 and year 3 because year 1 students has not yet studied any other basic sciences except for anatomy while year 3 students have nearly finished all of basic sciences. As a consequence, we are able to get useful feedback from the different stage of medical students after they underwent the integrated courses.

In this study, we would like to focus on the effect of the integrated courses and feedback of medical students, so that analyzed the exam results and questionnaire from year 1 and year 3 participant students. The exam results clearly showed that the year 3 participant students got much higher scores than the ones from year 1 students in the exams of both systems. The direct reaction is that nearly all of year 3 participant students (97\%) are supportive to the integrated courses while the positive attitude down to $74 \%$ in year 1 students since quite a lot year 1 students are negative. The result suggests that it would be better for operating integrated courses after the medical students obtained some basic scientific knowledge at year 3. In order to further address what caused the exam difference between year 1 and year 3 students, the questionnaire would be carried out among the participant students. In the multiple options of the questionnaire, the most dominant diversity is that year 1 participant students felt more difficulty to understand the contents of the courses than year 3 students, which also reflected the tendency of exam results in both populations of participants. Moreover, we compared first-year students' means scores between the integrated and conventional medical courses. The result also showed that the first-year students got higher scores in conventional courses than in integrated courses, indicating that the first-year medical students had more difficulties to study integrated curricula. Therefore, the better study effect on integration of some basic science into clinical medicine at year 3 students was observed than at year 1 students. Croen reported that the program of integration of basic science and clinical medicine for year 3 students at Albert Einstein College was successful since the students are able to apply basic science concepts and principles to clinical problems well (Croen, Lief, \& Frishman, 1986). The reform program at University of Pittsburgh School of Medicine was to integrate basic science knowledge into clinical teaching during the fourth year of medical school, and the authors also thought that senior medical students are better able to appreciate the relevance of basic science concepts to clinical medicines (Spencer, Brosenitsch, Levine, \& Kanter, 2008). The two reports are generally consistent with our observation in this study although they did not optimal time for open the integrated curriculum to the senior students with the junior students. Our results suggest that senior medical students might be more appropriate for integrating some aspects of basic science into medical medicine throughout two years, while fully integrating basic science teaching from freshmen may be not more effective.

It is speculated that the disadvantages for first-year students to begin the vertical integrated curriculum are as follow. First, they are still lacking basic medical science knowledge. Second, it is also hard for them to study any integrated curriculum, which is involved in six or seven medical courses of basic science and clinical medicine. Third, because of the reasons above, they don't have enough capability to master depth and width of the PBL questions. And it is very difficult for them to establish organic relations among different systems if they only learned one or two integrated curricula. Actually, as we know, there are very close relationship within many human systems, such as central nervous system, peripheral nervous system, and locomotor system, as well as nervous system, endocrine system, and reproductive system.

Furthermore, we assessed whether or not the integrated courses is helpful for improving the medical students' ability to diagnose and treat clinical diseases, because the final purpose of modern medical education is to foster qualified physicians. To assess this, when the first participant students entered clinical course study 2 year later, we employed OSCE (Fincham, \& Shuler, 2001; Patrício, Julião, Fareleira, \& Carneiro, 2013), in which the ability of applying knowledge and skills of medical students was objectively and professionally evaluated, i.e., reducing the subjectivity, occasionality and variability in the traditional exams. The contents of OSCE in this study were chosen based on the clinical skill practice and integrative analysis ability. In comparison to the non-participant students (control), the 
students who participated in integrated courses did not show any improvement in thoracentesis, lumbar puncture, bone marrow puncture, abdominocentesis, physical examination, analysis of ECG, cardiopulmonary resuscitation, gynecologic examination, surgical stitches and dressing, surgical discission and suture; but it did enhance the capability of those students' pediatrics history taking and clinical case analysis, which indicated that the integrated courses indeed improved analytical thinking skills of the participant students. Meanwhile, it is not surprising to observe that the integrated courses did not influence the handy skills in clinic. Interestingly, we found that there was not difference on traditional exam scores of internal medicine between the participant students and non-participant students, which implies that the integrated courses did not impact on the study of conventional single discipline.

\section{Conclusion}

In sum, our current study indicated that integrated course is truly instrumental for enhancing medical students' analytical ability. Moreover, year 3 is the optimal timing taking integrated course, after students have mastered quite basic science knowledge although the precise analysis work on each specialization should be further completed later on. It is more effective to begin the vertical integrated curriculum on senior medical students in comparison to freshmen medical students. We will keep exploring the other optimal conditions for the implementation of integrated courses based on the conventional medical education in the future.

\section{Competing Interests}

The authors declare that there are no conflicts of interest.

\section{Acknowledgments}

This study was supported by Chinese Outstanding Doctors' Training Program of Ministry of Education (120) and Education Reform Funding of Jinan University (88016309247).

\section{References}

Abraham, R.R., Vinod, P., Kamath, M.G., Asha, K., \& Ramnarayan, K. (2008). Learning approaches of undergraduate medical students to physiology in a non-PBL- and partially PBL-oriented curriculum. Advances in Physiology Education, 32(1), 35-37. http://dx.doi.org/10.1152/advan.00063.2007.

Bandiera, G., Boucher, A., Neville, A., Kuper, A., \& Hodges, B. (2013). Integration and timing of basic and clinical sciences education. Med Teach, 35(5):381-387. http:// dx.doi.org/10.3109/0142159X.2013. 769674

Brynhildsen, J., Dahle, L.O., Behrbohm, Fallsberg. M., Rundquist, I., \& Hammar, M. (2002). Attitudes among students and teachers on vertical integration between clinical medicine and basic science within a problem-based undergraduate medical curriculum. Medical Teacher, 24(3), 286-288. http://dx.doi.org/ $10.1080 / 01421590220134105$

Chen, C.S., Lai, C.S., Lu, P.Y., Tsai, J.C., Chiang, H.C., Huang, I.T., \& Yu, H.S. (2008). Performance anxiety at English PBL groups among Taiwanese medical students: a preliminary study. The Kaohsiung Journal of Medical Sciences, 24(3 Suppl), S54-58. http://dx.doi.org/10.1016/S1607-551X(08)70095-0

Croen, L.G., Lief, P.D., \& Frishman, W.H. (1986). Integrating basic science and clinical teaching for third-year medical students. Journal of Medical Education, 61(6), 444-453. Retrieved from http://journals.lww.com/academicmedicine/Abstract/1986/06000/Integrating_basic_science_and_clinical_teachi ng.2.aspx

Dahle, L.O., Brynhildsen, J., Behrbohm, Fallsberg. M., Rundquist, I., \& Hammar, M. (2002). Pros and cons of vertical integration between clinical medicine and basic science within a problem-based undergraduate medical curriculum: examples and experiences from Linkoping, Sweden. Medical Teacher, 24(3), 280-285. http://dx.doi.org/10.1080/01421590220134097

Davis, M.H., \& Harden, R.M. (2003). Planning and implementing an undergraduate medical curriculum: the lessons learned. Medical Teacher, 25(6), 596-608. http://dx.doi.org/10.1080/ 0142159032000144383

Fincham, A.G., \& Shuler, C.F. (2001). The changing face of dental education: the impact of PBL. Jouornal of Dental Education, 65(5), 406-421. Retrieved from http://www.jdentaled.org/content/65/5/406.long

Huang, L., Cheng, L., Cai, Q., Kosik, R.O., Huang, Y., Zhao, X., Xu, G.T., Su, T.P., Chiu, A.W., \& Fan, A.P. (2014). Curriculum reform at Chinese medical schools: what have we learned? Medical Teacher, 36(12), 1043-1050. http://dx.doi.org/10.3109/0142159X.2014.918253.

Jones, A., McArdle, P.J., \& O'Neill, P.A. (2002). Perceptions of how well graduates are prepared for the role of 
pre-registration house officer: a comparison of outcomes from a traditional and an integrated PBL curriculum. Medical Education, 36(1), 16-25. http://dx.doi.org/10.1046/j.1365-2923.2002.01105.x

Lie, N. (1995). Traditional and non-traditional curricula. Definitions and terminology. Tidsskrift for den Norske Laegeforening, 115(9), 1067-1071. Retrieved from http://europepmc.org/abstract/med/7725287

Muller, J.H., Jain, S., Loeser, H., \& Irby, D.M. (2008). Lessons learned about integrating a medical school curriculum: perceptions of students, faculty and curriculum leaders. Medical Education, 42(8) , 778-785. http://dx.doi.org/10.1111/j.1365-2923.2008.03110.x

Muller, S. (1984). Physicians for the twenty-first century. Report of the Project Panel on the General Professional Education of the Physician and College Preparation for Medicine. Journal of Medical Education, 59(11 Pt 2), 1-208. Retrieved from http://eric.ed.gov/?id=ED252102

Oda, Y., \& Koizumi, S. (2008). Status of medical education reform at Saga Medical School 5 years after introducing PBL. The Kaohsiung Journal of Medical Sciences, 24(3 Suppl), S46-53. http://dx.doi.org/10.1016/S1607-551X(08)70094-9

Patel, V.L., \& Dauphinee, W.D. (1984). Return to basic sciences after clinical experience in undergraduate medical training. Medical Education, 18(4), 244-248. Retrieved from http://onlinelibrary.wiley.com/doi/10.1111/j.1365-2923.1984.tb01018.x/pdf

Patrício, M.F., Julião, M., Fareleira, F., \& Carneiro A.V. (2013). Is the OSCE a feasible tool to assess_competencies in undergraduate medical education? Med Teach, 35(6):503-514. http://dx.doi.org /10.3109/0142159X.2013.774330.

Pipas, C.F., Peltier, D.A., Fall, L.H., Olson, A.L., Mahoney, J.F., Skochelak, S.E., \& Gjerde, C.L. (2004). Collaborating to integrate curriculum in primary care medical education: successes and challenges from three US medical schools. Family Medicine, 36 (Suppl S1), 26-32. Retrieved from https://www.stfm.org/fmhub/fm2004/January/CatherineS126.pdf

Rajan,S.J., Jacob, T.M., \& Sathyendra, S. (2016). Vertical_integration_of_basic_science in final year of medical education. Int J Appl Basic Med Res, 6(3):182-185. http://dx.doi.org/10.4103/2229-516X. 186958.

Rao, K.H., \& Rao, R.H. (2007). Perspectives in medical education 5. Implementing a more integrated, interactive and interesting curriculum to improve Japanese medical education. The Keio Joournal of Medicine, 56(3), 75-84. Retrieved from https://www.jstage.jst.go.jp/article/kjm/56/3/56_3_75/_pdf

Spencer, A.L., Brosenitsch, T., Levine, A.S., \& Kanter, S.L. (2008). Back to the basic sciences: an innovative approach to teaching senior medical students how best to integrate basic science and clinical medicine. Academic Medicine, 83(7), 662-669. http://dx.doi.org/10.1097/ACM.0b013e318178356b. 